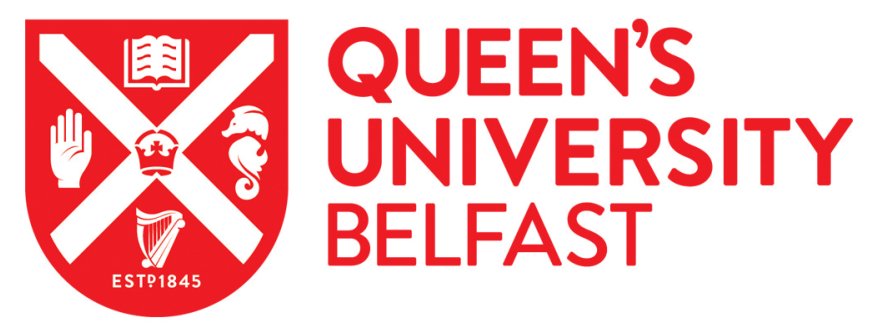

\title{
GP perceptions of the adequacy of community-based care for patients with advanced heart failure in a UK region (NI): a qualitative study
}

Chen, J. J., Gamble, K., Graham-Wisener, L., McGlade, K., Doherty, J., Donnelly, P., \& Stone, C. A. (2018). GP perceptions of the adequacy of community-based care for patients with advanced heart failure in a UK region (NI): a qualitative study. Open Heart, 5(1), [e000734]. https://doi.org/10.1136/openhrt-2017-000734

\section{Published in:}

Open Heart

Document Version:

Publisher's PDF, also known as Version of record

Queen's University Belfast - Research Portal:

Link to publication record in Queen's University Belfast Research Portal

\section{Publisher rights}

Copyright 2018 the authors.

This is an open access Creative Commons Attribution-NonCommercial License (https://creativecommons.org/licenses/by-nc/4.0/), which permits use, distribution and reproduction for non-commercial purposes, provided the author and source are cited.

\section{General rights}

Copyright for the publications made accessible via the Queen's University Belfast Research Portal is retained by the author(s) and / or other copyright owners and it is a condition of accessing these publications that users recognise and abide by the legal requirements associated with these rights.

Take down policy

The Research Portal is Queen's institutional repository that provides access to Queen's research output. Every effort has been made to ensure that content in the Research Portal does not infringe any person's rights, or applicable UK laws. If you discover content in the Research Portal that you believe breaches copyright or violates any law, please contact openaccess@qub.ac.uk. 


\title{
openheart GP perceptions of the adequacy of community-based care for patients with advanced heart failure in a UK region (NI): a qualitative study
}

\author{
Jingwen Jessica Chen, ${ }^{1}$ Kathryn Gamble, ${ }^{1}$ Lisa Graham-Wisener, ${ }^{2}$ \\ Kieran McGlade, ${ }^{1}$ Jennifer Doherty, ${ }^{2}$ Patrick Donnelly, ${ }^{3}$ Carol A Stone ${ }^{2}$
}

\begin{abstract}
- Additional material is published online only. To view please visit the journal online (http://dx.doi.org/10.1136/ openhrt-2017-000734).
\end{abstract}

To cite: Chen JJ, Gamble K, Graham-Wisener L, et al. GP perceptions of the adequacy of community-based care for patients with advanced heart failure in a UK region (NI): a qualitative study. Open Heart 2018;5:e000734. doi:10.1136/ openhrt-2017-000734

Received 9 0ctober 2017 Revised 19 February 2018 Accepted 21 March 2018
Check for updates

${ }^{1}$ Queen's University Belfast, Belfast, UK

${ }^{2}$ Marie Curie Hospice Belfast, Belfast, UK

${ }^{3}$ Department of Cardiology, South Eastern Health and Social Care Trust, Ulster Hospital, Dundonald, UK

Correspondence to

Dr Carol A Stone; carol.stone@ mariecurie.org.uk

\section{ABSTRACT}

Objective To assess the adequacy of community-based services available in Northern Ireland (NI) and to meet the multidimensional needs of patients living with New York Heart Association Stage III and IV heart failure (HF), as experienced and perceived by general practitioners (GP). Methods Semistructured interviews were conducted with GPs recruited via the University Department of General Practice and Northern Ireland Medical and Dental Agency. Interviews were transcribed, independently coded and analysed using a six-step thematic analysis approach. Results Twenty semistructured interviews were conducted. GPs reported managing patients in a 'reactive rather than proactive' way, responding only to acute medical needs, with hospital admission the default option due to lack of community-based expertise and services. Care provided by HF specialists was highly regarded but 'access and coordination' were lacking, related to inequity of access to Heart Failure Nursing Teams, lack of access to specialist advice and inadequate handover of information to GPs. Conversations regarding current and future care needs and preferences were important, but GPs described 'neglecting conversations with the patient', due to time constraints, prognostic uncertainty and fear of causing distress. They expressed the view that 'specialist palliative care (SPC) is only a credible option in end stages' related to limited understanding of the scope of SPC, a perception that timing of referral must depend on prognosis and concern that SPC services are cancer-focused.

Conclusions Despite the extensive body of research which evidences the unmet multidimensional needs of patients with advanced HF, and more recent evidence for the effectiveness of integrated SPC in improving quality of life for patients with HF, health and social care services within $\mathrm{NI}$ have not adapted to assess and meet these needs.

\section{INTRODUCTION}

Heart failure (HF) is a disease which predominantly affects older people. It is estimated that $13.7 \%$ of men and $12.5 \%$ of women aged $>75$ years in the UK live with $\mathrm{HF}$; the median age of patients admitted to hospital because of $\mathrm{HF}$ is 80 years. ${ }^{1}$ The prevalence of fatigue $(69 \%-92 \%)$, dyspnoea $(60 \%-88 \%)$ and pain

\section{Key questions}

What is already known about this subject?

- Numerous research reports document the burden of uncontrolled symptoms, psychological distress and physical dependency associated with advanced heart failure (HF). However, traditional models of care for patients with HF are medically focused and patients have poor access to specialist palliative care (SPC) services

What does this study add?

- There is no evidence of service development within health and social care services in Northern Ireland, in recognition and response to the complex unmet needs of patients with symptomatic stage III and IV HF. Barriers to progress and enabling factors are discussed.

How might this impact on clinical practice?

- Interprofessional collaboration on service planning, education and communication strategies between cardiology, SPC and general practice is key to addressing many of the issues identified in this study.

(44\%-77\%) are comparable to symptom prevalence in populations with advanced cancer. ${ }^{2}$ Reduced performance status, dependency on others, social isolation, anxiety and depression are common. ${ }^{3}$ The prognosis is poor; $30 \%-40 \%$ of patients diagnosed with HF die within a year. ${ }^{4}$ The classically described disease trajectory is characterised by a slow decline, punctuated by sudden dips in functioning related to acute exacerbations, from which the patient has a risk of dying, or recovering. ${ }^{5}$ Accordingly, prognostication is challenging, and widely used tools have been shown to be inaccurate at predicting survival of $<12$ months. ${ }^{6}$

The multidimensional needs of patients with advanced cancer are well recognised. Responsive services have been developed 
to meet these needs and the value of early integrated specialist palliative care (SPC) with oncological treatment is increasingly acknowledged. Patients with cancer constitute the vast majority of those accessing SPC services, with many others receiving care delivered using a palliative care approach from general practitioners (GPs) and other specialists. ${ }^{7-9}$

In comparison, conventional models of care for patients with $\mathrm{HF}$ are typically medically focused. Cardiologists perceive themselves to be poor at recognising palliative care needs and describe not prioritising communication regarding the implications and impact of worsening disease. ${ }^{10}$ Research studies conducted during the past two decades have identified that patients with HF experience poor communication regarding the nature of their disease and what to expect. This adversely impacts on their ability to make informed life and healthcare choices and prepare themselves and family members for death. ${ }^{11}$ They report inadequate support in dealing with psychosocial distress and cite inadequacies in care planning and health service availability after hospital discharge. ${ }^{10}$

There is emerging evidence for the effectiveness of integrating systematic assessment of palliative care needs and SPC with traditional HF management, in improving symptoms, quality of life (QOL) and hospital readmission rates. ${ }^{12-16}$ However, such models seem to exist mainly within the context of research studies or at the instigation of interested individuals. ${ }^{17}$

The actual numbers of patients with HF referred to SPC across the UK are small. ${ }^{8}$ Anecdotally, within Northern Ireland (NI), few such patients are referred to SPC services. However, it is unknown whether patients with HF have access to holistic care delivered by non-palliative care specialists using a palliative care approach and whether community-based systems and services, outwith SPC, have improved and adapted to better meet the emotional, social, functional and medical needs of patients with $\mathrm{HF}$ and their families.

This information is urgently needed. GPs perceive themselves to be well placed to assess the multidimensional needs of patients and their families within the community and on average look after 30 patients with HF per annum. ${ }^{10} 18$

\section{AIMS AND OBJECTIVES}

To assess the adequacy of community-based health and social care services available in NI, to meet the emotional, practical and social care needs, in addition to medical needs, of patients living with New York Heart Association (NYHA) stage III and IV HF, as experienced and perceived by GPs.

\section{METHODS}

A qualitative design was used, using semistructured telephone interviews with GPs in NI. This paper followed the
Consolidated criteria for Reporting Qualitative research (COREQ) guidelines for reporting qualitative research.

\section{Participants and recruitment}

GPs involved in undergraduate and/or postgraduate teaching in NI were invited to participate via the Department of General Practice of Queen's University Belfast and the Northern Ireland Medical and Dental Training Agency, respectively. GPs received a letter of invitation and participant information sheet by email. There was no exclusion criterion. Maximum variation sampling, a purposeful technique designed to capture as diverse a range of viewpoints as possible, was used to ensure GPs from each of the five regional Health and Social Care (HSC) Trust areas were included. This type of purposive sampling accommodated different perspectives resulting from variation in local health and social care service provision.

\section{Data collection}

Data were collected by JJC and KG using semistructured interviews between June and August 2016. A pilot faceto-face interview was conducted with no refinement of the interview schedule needed. The interviews were conducted by telephone following the interview guide (see online supplementary appendix 1). Consent was obtained and recorded prior to the interview. Interviews were audio-recorded and supplemented by field notes. The mean interview length was $22 \mathrm{~min}$. The interviewers offered to summarise the discussion at the end of each interview. Interview recordings were transcribed verbatim by JJC and KG and transcripts returned to the participants for comment and/or correction. There was no previous contact between JJC, KG and the study participants.

\section{Data analysis}

The transcribed interviews were entered into NVivo V.9 (QRS international), coded and analysed using a six-stage thematic analysis. ${ }^{19}$ Key themes were identified inductively to ensure they were strongly aligned to the raw data. An essentialist approach was adopted as only what was explicitly discussed by the participant was of interest, and not anything beyond this. ${ }^{19} 20$ Initial codes were revised until data saturation appeared to have been reached, that is, when no new emergent themes were attained from analysis. The number of interviews was determined by reaching data saturation. Techniques to ensure validity and enhance rigour included independent coding of data by JJC and KG, assessing agreement on emergent codes and differences resolved through discussion.

\section{RESULTS}

Twenty-four GPs responded to the letter of invitation. Data saturation was reached after 14 interviews: six subsequent interviews were undertaken for confirmation of themes. Details of participant characteristics are summarised in table 1 . 
Table 1 Participant demographic data

\begin{tabular}{|c|c|}
\hline \multicolumn{2}{|c|}{ Participant characteristic $(n=20)$} \\
\hline Gender & 10 males, 10 females \\
\hline Age range & $31-61$ years \\
\hline $\begin{array}{l}\text { Years practising as } \\
\text { general practitioner }\end{array}$ & $90 \%>10$ years (range $3-30$ years). \\
\hline $\begin{array}{l}\text { Experience outside of } \\
\text { general practice }\end{array}$ & $\begin{array}{l}\text { Four in specialist palliative care, one with } \\
\text { special interest in heart failure }\end{array}$ \\
\hline \multicolumn{2}{|c|}{ Practice characteristic $(n=20)$} \\
\hline $\begin{array}{l}\text { Health and Social Care } \\
\text { Trust }\end{array}$ & $\begin{array}{l}7 \text { Belfast, } 6 \text { South Eastern, } 4 \text { Northern, } 2 \\
\text { Western, } 1 \text { Southern }\end{array}$ \\
\hline Location & 17 urban, 3 rural \\
\hline Funding & 20 National Health Service \\
\hline $\begin{array}{l}\text { Patients per } \\
\text { general practitioner in } \\
\text { practice }\end{array}$ & 1500-2700 patients \\
\hline
\end{tabular}

The following themes and subthemes were identified from the data. Quotations illustrating the findings are presented from the full-text transcripts.

\section{Reactive versus proactive}

\section{GPs responsive to acute problems}

GPs reported awareness of and responsiveness to acute medical problems, with more chronic needs such as the psychological, social and practical needs of patients with advanced HF often being overlooked: 'It's hard to think about that side of things, with medications and U\&E's [serum urea \& electrolytes], and all of that, and you sort of forget that there's a more human side of it' (P19). Time constraints were addressed as a significant factor contributing to lack of identification and realisation of these needs, as were competing demands related to multiple comorbidities.

\section{Default hospital admission}

GPs reported that in their experience exacerbations of HF commonly result in admission to hospital, medical treatment and discharge, with no alterations in social care provision or long-term considerations. Participants described that patients are not generally reviewed by a cardiologist during admission and that such patients, if not already known to a cardiologist, cannot access the HF team in the community. Hospital admission was described as a means 'to basically sort of, fire fight, sort this problem out, adjust the medication and then home' (P01). GPs felt there were a number of reasons for this approach to care. First, hospital admission was often seen as the default management option: 'The easy thing is to arrange an ambulance without even assessing them' (P01). This was related to the view that admission to hospital ensures appropriate expertise and medical treatment. Second, hospital admission was often described as the only option: 'There's sort of no in between, it's one or the other kind of thing. Wait for outpatient assessment or send them to casualty' (P05). A recurrently expressed opinion was that hospital admission should be viewed as the last resort. It was suggested that treatment in the community would be preferable if resources and expertise were available to facilitate this. The absence of processes to elicit patients' preferences for a palliative approach to care was also perceived to contribute to recurrent hospital admissions.

\section{Access and communication}

Difficulty accessing specialist cardiology services

The Community Heart Failure Nursing Teams (HFTs) in NI were highly praised by many GPs for their holistic care of patients in the community. However, resourcing of this service and equity of access were frequently cited as problematic. Access is largely limited to patients under the care of a cardiologist. As a result, patients awaiting first review by a cardiologist or who have been discharged from outpatient cardiology services due to reduced mobility related to advanced disease are disadvantaged. GPs also highlighted geographical variations, related to differences in provision by different Trusts. Many of these issues were related to resource limitations: 'Like getting ECHOs organised, very difficult, and again it's back to resources and time .... and just not enough people' (P01). Diagnosis and treatment of HF by cardiology following initial review were perceived as timely and appropriate. However, GPs described suboptimal interim treatment as the patient awaits outpatient assessment. Some GPs expressed a desire to refer patients directly for echocardiograms: This service is currently available in four out of the five Trust areas.

\section{Challenges in communicating with specialist cardiology services}

GPs recognised that patient care is optimised when there is (i) strong communication between primary and secondary care and (ii) training available for GPs on assessment and management of both medical and non-medical patient needs. However, GPs reported difficulty in contacting a consultant cardiologist directly in the absence of personal networks. 'Consultants now, their emails, their inboxes are bundled with emails and enquiries and quite often when you phone secretaries, you go straight to an answering machine, but if you're persistent enough, you tend to get what you need, but you need to be persistent you know' (P14). GPs described poor communication, resulting in inadequate handover following discharge from the cardiology team. It was suggested that improved communication between cardiology services and general practice around the terms of discharge could improve future care. 'If it was initially discussed by the cardiologist who might also be able to answer, in more detail, any questions that the patient might have about, you know, any specific therapies available if their condition is deteriorating ... and then communicated to the primary care team in including the GP, yeah, I think that would be the ideal scenario' (P20). 
Inadequately responsive allied health services

Most participants recognised that community-based occupational therapy (OT), physiotherapy and psychological support are valuable in advanced HF management, available via the referral system, but are often not responsive. Some GPs were aware that for patients identified as palliative, waiting times might be shorter. OT in particular was described as having very long waiting times. Physiotherapy was perceived to have a limited role in advanced HF management, unless there were specific comorbidities requiring specialist physiotherapy support. Services providing psychological and emotional support in the community were unanimously reported as lacking or absent, instead 'largely coming from relatives, or loved ones, or me' (P12). GPs were concerned about the adequacy and suitability of generic community mental health services in supporting patients with HF.

\section{Neglecting conversations with the patient}

Palliative transition difficult to identify

GPs felt that HF was generally not viewed as a terminal condition requiring palliation by both patients and healthcare workers. 'Patients just see it as another medical problem, that just gets treated, but I don't think they necessarily look into the future, or see it as something that could shorten or bring their life to a close you know, I don't think the medical profession view it quite that way either!' (P14). Yet, it was noted that this perception is changing among healthcare workers and that there is increasing awareness of the palliative needs of these patients. Lack of a clear transition point in the disease trajectory was identified as a barrier to adoption of a palliative approach to care and comparisons were made with the cancer disease trajectory, whereby lack of response to treatment is a relatively clear cut marker for the transition to a palliative approach. It was suggested that guidelines or screening questions to be used at annual review might be helpful.

\section{Who takes responsibility for initiation?}

Many GPs addressed the importance of having discussions with patients about the progressive nature of $\mathrm{HF}$, the prognosis and to elicit patients' future care preferences. However, it was reported that these discussions occurred infrequently and late in the disease course. Many stated that they would be willing to undertake these conversations, but that it is unusual for them to initiate such discussions. 'Again, I think we are always led by how proactive the patient is and whether the patient wishes to communicate or talk about what their implications of their diagnosis really are' (P05). A number of participants did not perceive a need for discussions with patients. Others suggested that responsibility lies with the cardiologist, or that the heart failure nurse may assume this task. Whether the conversation occurred seemed to be left to chance, 'So it really depends on who they've been, what service or what consultant they have been lucky enough to see or what clinics they have been referred to' (P11). Some GPs stated that patients simply do not wish to discuss end of life care. Others acknowledged their discomfort in having these conversations and subsequent avoidance, 'Easy to duck out of it and leave it to the next time or the next person ... it's not a conversation you want to start up, but that doesn't mean it shouldn't happen' (P01). In addition, more practical barriers, such as time constraints and availability of healthcare workers, were identified. Some GPs reported local enhanced service initiatives which give financial incentives to increase consultation length and end-of-life care planning for patients with multiple comorbidities.

\section{Fear of getting it wrong}

The unpredictable prognosis associated with HF was described as a barrier to initiating conversations with patients due to a fear of labelling a patient as palliative too early in the disease course: 'Because even hospital consultants find it difficult to prognosticate about these patients, that they're reluctant to somehow write them off by having frank conversations with them' (P09). This fear of labelling encompassed a fear of limiting future active treatment and of causing unnecessary anxiety. GPs described this 'prognostic paralysis' often resulting in conversations being deferred until terminal stages of the illness. Other barriers were the fear that these conversations would be met with resistance from the patient and difficulty in communicating the rationale for transition to a palliative care approach.

\section{SPC only a credible option in end stages}

Domiciliary rather than hospice-based services

Most GPs perceived that SPC services should be delivered in the community, mainly due to patients' restricted mobility limiting their ability to travel. 'At the stage where we're saying this patient is palliative with congestive $\mathrm{HF}$, normally they are not in a situation where they can really attend clinic' (P09). Geographical location, distance from rural practices, long waiting lists and patient reluctance emerged as additional barriers to referral and access to hospice-based services, such as outpatient and day hospice services.

\section{SPC playing a key part in the terminal stages}

Overall, GPs acknowledged that SPC services are relevant and appropriate. However, most stated that these services are more acceptable to the patient at the very end stages of $\mathrm{HF}$, when the condition no longer improves despite optimisation of medical therapy; 'the penny drops that they're (patient) not going to get any better, that's whenever they'd be more receptive, you know, to palliative care services' (P08). GPs appreciate the focus SPC services place on delivering holistic care, with priority placed on symptom control and maximising QOL. Most GPs also value the role SPC services play in providing psychological and emotional support for patients, family and carers.

\section{Lack of experience in $\mathrm{HF}$}

Almost all GPs perceived SPG services to be expert in treating cancer patients and configured to meet the needs 
of this patient population. In contrast, they perceived lack of proficiency in the management of HF, which may partly contribute to a diminished willingness to refer. 'So the hospice deal with a lot of chronic pain, em but the symptomatology of HF is really fatigue, feelings of breathlessness and oxygen needs, you know. It doesn't really kind of fit with the hospice, kind of forte, if you get what I mean' (P16). Training of community-based SPC nurses in HF management or of existing community heart failure nurses in palliative care were both heralded as solutions.

\section{DISCUSSION}

Within the emergent themes from this study, a number of barriers to the provision of holistic care for patients with HF in NI are described. The barriers identified encompass (i) under-resourcing of community-based services and dependence on stretched secondary care services, (ii) the impact of prognostic paralysis and lack of confidence in communicating uncertainty, (iii) medical culture of care with an emphasis on fixing problems and (iv) a limited understanding of what SPC has to offer and limited sharing of expertise between general practice, cardiology and SPC. These findings are not novel, but rather they echo themes arising from systematic reviews of research on healthcare professionals' (HCPs') perceptions of provision of palliative care in HF spanning 17 years. ${ }^{3} 1011$ Doctors who participated in the study conducted by Hanratty et al published in 2002 identified the unpredictable course of HF, doctors' poor understanding of roles and the organisation of healthcare services as barriers to provision of palliative care for people with HF. Key priorities identified were better support for primary care and enhanced communication between all HCPs. ${ }^{21}$ Our findings are consistent with other more recent research. HCPs who participated in the study by Glogowska et al recognised the pivotal importance of conversations with patients with HF regarding what they might expect from their disease, and the negative impact of reluctance, on the part of HCPs, to have these conversations. The need to avoid and find alternatives to the default position of hospital admission for deteriorating patients also emerged as a key theme. ${ }^{22}$ This suggests that little progress has been made in addressing the shortcomings in provision of holistic care for patients with $\mathrm{HF}$ in NI. A report published recently by Hospice UK suggests that the situation may be similar throughout the UK. ${ }^{17}$ It is likely that the complexity and number of barriers and the involvement of multiple agencies underlie this lack of progress.

Participants expressed the opinion that patients with HF would be better served by community-based care if the necessary expertise and services were available. GPs are not alone in their desire to see an expanded range of services provided within primary care: this forms a central tenet of National Health Service and government policy; viewed as key to sustainable and more patient-centred healthcare. ${ }^{23}{ }^{24}$ Yet, realisation of enhanced primary care is undermined by the ongoing crisis in staffing in general practice and district nursing and necessitates increased investment in the community. ${ }^{25}$ GPs value the role of HFTs in providing holistic care, but described access restricted to those under review by a cardiologist, disadvantaging those awaiting first review, and patients with reduced mobility or on maximal therapy. Inadequate numbers of specialist nurses and lack of time provision within consultant job plans to support patients in the community underlie these restrictions. GPs perceived that obtaining advice from a consultant cardiologist would empower them to better manage patients with HF. This perception is backed up by evidence; a Nuffield Trust Research Report published this year found that allowing GPs access to specialist expertise has a strong positive effect on reducing referrals for elective secondary care. ${ }^{25}$ A lack of communication between primary and secondary care also detracts from the quality and continuity of care that patients receive. This relates to the absence of systems to notify GPs of discharge from cardiology or the HFT, and to handover key information regarding medical care, patient insight and care preferences.

GPs participating in this study referred to a growing acknowledgement, among HCPs, of the terminal nature of $\mathrm{HF}$ and the palliative needs of patients with HF. However, it appears that due to the inherent difficulty in prognosticating and fear of getting this wrong, this has not impacted on clinical practice. Indeed, articulation of a possible short prognosis was equated with 'writing them off', with HCPs leaving patients to work it out by themselves that they are not getting any better, waiting until 'the penny drops'. A systematic review of studies investigating the nature of end-of-life discussions between HCPs and patients with HF, published in 2011, concluded that these rarely take place and that conversations between clinicians and patients largely focus on disease management. ${ }^{11}$ The reasons provided by HCPs for avoiding conversations, cited in this and more recent systematic reviews, include lack of time, prognostic uncertainty, perceived lack of communication skills and fear of causing distress unnecessarily, and are consistent with our findings. ${ }^{1026}$ However, the American Heart Association recommends that prognostic uncertainty should itself serve as a trigger for discussions with patients. ${ }^{27}$ They recommend that, rather than avoiding mentioning our concern that time may be short, lest we are wrong, we share information with patients regarding the difficulty in predicting the exact course that their disease may take and the uncertainty regarding survival. Some participating GPs confessed to feeling ill-equipped to have end-of-life conversations with patients. A variety of communication skills training courses have been developed for HCPs working with patients with cancer, which focus on improving skills in breaking bad news, eliciting patients' concerns and managing emotional responses, both in ourselves and patients. ${ }^{28}$ GPs and heart failure specialists must be supported to develop and maintain these skills. 
GPs participating in this study did not view SPC as a viable option for patients with HF. This related to the commonly held view that referral must be based on estimation of short survival and the limited understanding of how SPC can support patients at an earlier stage in the course of their disease. Similarly, HCPs working in the USA interviewed by Kavalieratos et al regarding the barriers to referral of patients with HF to SPC had limited knowledge of how palliative care might complement traditional HF management and perceived that palliative care was appropriate only for those close to death. ${ }^{29}$ It has been proposed that having a prognosis-based criterion for referral of patients with HF to SPC serves to inhibit rather than assist appropriate referrals. Our findings support this. Instead, it is recommended that receipt of palliative care, whether in the guise of care provided by GPs or HFTs using a palliative care approach, or SPC, should be based on need. ${ }^{17}$ 30-32 Triggers for assessment of unmet palliative needs include prognostic uncertainty, intractable symptoms such as breathlessness, frequent hospitalisations and multiple comorbidities. ${ }^{33}$ Discussion with patients regarding their needs, and how SPC services could meet these, might facilitate a more meaningful and positive introduction to SPC for patients and families. GPs had limited understanding of the scope of practice within SPC. The development of hospice services within the voluntary sector, with limited opportunities for GPs to rotate through SPC services, has probably contributed to this; the situation is probably similar for cardiologists. ${ }^{34}$ Randomised controlled trials (RCTs) of palliative care interventions for patients with life-limiting illnesses demonstrate that palliative care provision is associated with improved QOL and symptom control, greater patient and caregiver satisfaction and participation in advanced care planning. ${ }^{35}$ Evidence for the effectiveness of palliative care interventions for patients with HF is slowly emerging. ${ }^{36}$ Two RCTs of palliative care interventions for community-dwelling patients with NYHA III or IV HF have evidenced improvement in health-related QOL, depression, dyspnoea, total symptom burden, improved NYHA class and lower readmission rates, compared with usual care. $^{12} 13$ The recently published PAL-HF RCT demonstrated improved anxiety and spiritual well-being, in addition to benefits to QOL and depression in patients with HF randomised to receive a palliative care intervention in addition to standard care. ${ }^{37}$

This study provides important insight into the issues affecting GPs managing patients with advanced HF in the community. The study has a number of strengths, including a robust design with an adequate sample of GPs from across the region. The transparency of reporting using COREQ guidelines provides evidence of the validity of the findings. The aim of the current study was to understand the adequacy of current service provision for patients with HF from the perspective of the GP. Patients with advanced $\mathrm{HF}$ and their carers may perceive and experience this differently. In order to ensure a patient-centred approach to service development, the current study would be usefully supplemented by qualitative enquiry with patients and carers with HF across the region, alongside health services utilisation data. In one study, conducted with patients with life-limiting non-malignant conditions including HF in NI, patients expressed frustration at delays in accessing equipment, inadequate provision of psychological support and access to SPC, and described the difficulties presented by uncontrolled symptoms and concerns for the future. ${ }^{38}$ The study was conducted more than a decade ago, yet the service limitations as articulated by GPs today are very similar.

Maximum variation sampling ensured that perspectives of GPs from each of the five regional HSC Trust areas were captured, reflecting variation in local health and social care service needs and provision. The majority of participating GPs in this study however were based in urban practices. GPs involved may also have had an interest in education. These factors may introduce an element of bias and limit the generalisability of findings to the GP population at large. Nonetheless, adopting a pragmatic approach to recruitment is important to facilitate higher participation rates among GPs, a group known to be difficult to recruit. ${ }^{39} 40$

Recognition of the value of early integrated palliative care for patients receiving palliative oncology treatments did not happen overnight. ${ }^{41}$ Interprofessional collaboration on service planning, education and communication strategies between cardiology, SPC and general practice is key to addressing many of the issues identified in this study. ${ }^{17}$ Allocation of a key worker, such as a community-based SPC nurse trained in HF, will likely enhance coordination of care. ${ }^{42}{ }^{43}$ SPC HCPs are ideally placed to provide training in communication skills, assessment of palliative care needs and symptom management. SPC providers must also address concerns that services are cancer focused and improve at telling people what they do.

Contributors CAS, LG-W, JD, KMG and PD: study concepts and design. LG-W and CAS: protocol design. KMG and CAS: GP recruitment. JJC and KG: qualitative interviews and coding data and thematic analysis. JJC, KG, CS, LG-W and KMG: manuscript preparation, editing and review. JJC and KG contributed equally to this paper. All authors approved the final version of this manuscript.

Funding This work was undertaken as part of a summer studentship funded by Marie Curie and Centre for Medical Education, Queen's University Belfast.

Competing interests The hospice posts of LG-W, JD and CAS are supported by Marie Curie.

Patient consent Not required.

Ethics approval Ethics Committee of the School of Medicine, Dentistry and Biomedical Sciences, Queen's University Belfast.

Provenance and peer review Not commissioned; externally peer reviewed. Data sharing statement There are no additional data available for this paper.

Open Access This is an Open Access article distributed in accordance with the Creative Commons Attribution Non Commercial (CC BY-NC 4.0) license, which permits others to distribute, remix, adapt, build upon this work non-commercially, and license their derivative works on different terms, provided the original work is properly cited and the use is non-commercial. See: http://creativecommons.org/ licenses/by-nc/4.0/ 
(c) Article author(s) (or their employer(s) unless otherwise stated in the text of the article) 2018. All rights reserved. No commercial use is permitted unless otherwise expressly granted.

\section{REFERENCES}

1. British Society for the Heart Failure. National Heart Failure Audit. London: National Institute for Cardiovascular Outcomes Research (NICOR), 2013. (accessed 05 Jul 2017).

2. Solano JP, Gomes B, Higginson IJ. A comparison of symptom prevalence in far advanced cancer, AIDS, heart disease, chronic obstructive pulmonary disease and renal disease. J Pain Symptom Manage 2006;31:58-69.

3. Gadoud A, Jenkins SM, Hogg KJ. Palliative care for people with heart failure: summary of current evidence and future direction. Palliat Med 2013;27:822-8.

4. NICE guidelines. Chronic heart failure in adults: management. 2010. https://www.nice.org.uk/guidance/cg108/chapter/1-Guidance (accessed 20 Jul 2017).

5. Murray SA, Sheikh A. Care for all at the end of life. BMJ 2008;336:958.1-9.

6. Haga K, Murray S, Reid J, et al. Identifying community based chronic heart failure patients in the last year of life: a comparison of the Gold Standards Framework Prognostic Indicator Guide and the Seattle Heart Failure Model. Heart 2012:98:579-83.

7. Temel JS, Greer JA, Muzikansky A, et al. Early palliative care for patients with metastatic non-small-cell lung cancer. $N$ Engl J Med 2010;363:733-42

8. The National Council for Palliative Care. National survey of patient activity data for specialist palliative care services: minimum data Set 2014-15. 2017. http://www.ncpc.org.uk (accessed 09Jul 2017).

9. Quill TE, Abernethy AP. Generalist plus specialist palliative care-creating a more sustainable model. N Engl J Med 2013;368:1173-5.

10. Low J, Pattenden J, Candy B, et al. Palliative care in advanced hear failure: an international review of the perspectives of recipients and health professionals on care provision. J Card Fail 2011;17:231-52.

11. Barclay S, Momen N, Case-Upton S, et al. End-of-life care conversations with heart failure patients: a systematic literature review and narrative synthesis. Br J Gen Pract 2011;61:49-62.

12. Brännström M, Boman K. Effects of person-centred and integrated chronic heart failure and palliative home care. PREFER: a randomized controlled study. Eur J Heart Fail 2014;16:1142-51.

13. Wong FK, Ng AY, Lee PH, et al. Effects of a transitional palliative care model on patients with end-stage heart failure: a randomised controlled trial. Heart 2016;102:1100-8.

14. Sidebottom AC, Jorgenson $A$, Richards $\mathrm{H}$, et al. Inpatient palliative care for patients with acute heart failure: outcomes from a randomized trial. J Palliat Med 2015;18:134-42.

15. Diop MS, Rudolph JL, Zimmerman KM, et al. Palliative care interventions for patients with heart failure: a systematic review and meta-analysis. J Palliat Med 2017;20:84-92.

16. Kavalieratos D, Gelfman LP, Tycon LE, et al. Palliative care in heart failure: rationale, evidence, and future priorities. J Am Coll Cardiol 2017;70:1919-30.

17. Hospice UK. Heart failure and hospice care: how to make a difference. London: Hospice UK, 2017

18. Stewart S, Horowitz JD. Home-based intervention in congestive heart failure: long-term implications on readmission and survival. Circulation 2002;105:2861-6.

19. Braun V, Clarke V. Using thematic analysis in psychology. Qual Res Psychol 2006;3:77-101.

20. Barbour RS. The newfound credibility of qualitative research? Tales of technical essentialism and co-option. Qual Health Res 2003;13:1019-27.

21. Hanratty B, Hibbert D, Mair F, et al. Doctors' perceptions of palliative care for heart failure: focus group study. BMJ 2002;325:581-5.

22. Glogowska M, Simmonds R, McLachlan S, et al. "Sometimes we can't fix things": a qualitative study of health care professionals' perceptions of end of life care for patients with heart failure. BMC Palliat Care 2016;15:3.
23. NHS England, Public Health England, Health Education England, Monitor, Care Quality Commission, NHS Trust Development Authority. Five Year Forward View 2014. 2014. https://www.england. nhs.uk/publication/nhs-five-year-forward-view/ (accessed 2 Sep 2017).

24. Department of Health for Northern Ireland. Health and Wellbeing 2026: delivering together. 2016. https://www.health-ni.gov.uk sites/default/files/publications/health/health-and-wellbeing-2026delivering-together.pdf (accessed 28 Aug 2017).

25. Imison C, Curry N, Holder H, et al. Shifting the balance of care: great expectations research report. London: Nuffield Trust, 2017.

26. Oishi A, Murtagh FE. The challenges of uncertainty and interprofessional collaboration in palliative care for non-cancer patients in the community: a systematic review of views from patients, carers and health-care professionals. Palliat Med 2014;28:1081-98.

27. Braun LT, Grady KL, Kutner JS, et al. American Heart Association Advocacy Coordinating Committee. Palliative Care and Cardiovascular Disease and Stroke: a policy statement from the American Heart Association/American Stroke Association. Circulation 2016;134:e198-225.

28. Moore PM, Rivera Mercado S, Grez Artigues M, et al. Communication skills training for healthcare professionals working with people who have cancer. Cochrane Database Syst Rev 2013;28:CD003751.

29. Kavalieratos D, Mitchell EM, Carey TS, et al. 'Not the 'grim reaper service': an assessment of provider knowledge, attitudes, and perceptions regarding palliative care referral barriers in heart failure. J Am Heart Assoc 2014;3:e544:

30. Small N, Gardiner C, Barnes S, et al. Using a prediction of death in the next 12 months as a prompt for referral to palliative care acts to the detriment of patients with heart failure and chronic obstructive pulmonary disease. Palliat Med 2010;24:740-1.

31. Hogg KJ, Jenkins SM. Prognostication or identification of palliative needs in advanced heart failure: where should the focus lie? Heart 2012:98:523-4.

32. Costantini M, Higginson IJ, Merlo DF, et al. About the "surprise question". CMAJ 2017;189:E807

33. Triggers for Palliative care. Improving access to care for people with diseases other than cancer. Marie Curie 2015. London: Registered Charity, England and Wales, Scotland, 2015:44.

34. Clark D. Originating a movement: Cicely Saunders and the development of St Christopher's Hospice, 1957-1967. Mortality 1998;3:43-63.

35. Kavalieratos D, Corbelli J, Zhang D, et al. Association between palliative care and patient and caregiver outcomes: a systematic review and meta-analysis. JAMA 2016;316:2104-14

36. Kavalieratos D, Gelfman LP, Tycon LE, et al. Palliative care in heart failure: rationale, evidence, and future priorities. J Am Coll Cardiol 2017;70:1919-30.

37. Rogers JG, Patel CB, Mentz RJ, et al. Palliative care in heart failure: the pal-hf randomized, controlled clinical trial. J Am Coll Cardiol 2017:70:331-41.

38. Fitzsimons D, Mullan D, Wilson JS, et al. The challenge of patients' unmet palliative care needs in the final stages of chronic illness. Palliat Med 2007:21:313-22.

39. Asch S, Connor SE, Hamilton EG, et al. Problems in recruiting community-based physicians for health services research. J Gen Intern Med 2000;15:591-9.

40. Templeton L, Deehan A, Taylor C, et al. Surveying general practitioners: does a low response rate matter? Br J Gen Pract 1997;47:91-4.

41. Ferrell BR, Temel JS, Temin S, et al. Integration of palliative care into standard oncology care: American Society of clinical oncology clinical practice guideline update. J Clin Oncol 2017;35:96-112.

42. Daley A, Matthews $C$, Williams A. Heart failure and palliative care services working in partnership: report of a new model of care. Palliat Med 2006;20:593-601.

43. Johnson M. Planning for end-of-life care in heart failure: experience of two integrated cardiology-palliative care teams. $\mathrm{Br} J$ Cardiol 2012;19:71-5. 